\title{
Basic Geological and Geochemical Analysis in Wenquanbingzhan Area
}

\author{
Zheng Xiang Guang*, Lu Lin, Mao Yi Feng, Wang Chen, Meng Jun Feng \\ The Second Comprehensive Geophysical Survey Team Company, Shaanxi Bureau of Geology and Mineral Resources, Xi'an, China \\ Email address: \\ 748639323@qq.com (Zheng Xiang Guang),570065028@qq.com (Lu Lin), 254712151@qq.com (Mao Yi Feng), \\ 1050776474@qq.com (Wang Chen),286273663@qq.com (Meng Jun Feng) \\ ${ }^{*}$ Corresponding author
}

\section{To cite this article:}

Zheng Xiang Guang, Lu Lin, Mao Yi Feng, Wang Chen, Meng Jun Feng. Basic Geological and Geochemical Analysis in Wenquanbingzhan Area. Earth Sciences. Vol. 8, No. 4, 2019, pp. 217-227. doi: 10.11648/j.earth.20190804.11

Received: May 13, 2019; Accepted: June 25, 2019; Published: July 18, 2019

\begin{abstract}
According to the basic geology study, the feature of the element association and the analysis on characteristic element abnormal combination, we think that there are large scale intermediate-basic volcanic (subvolcanic) rocks with some medium acid intruded rocks or vein rocks groups by the work of 1 to 50000 scale geochemical exploration in the north Sanjiang-Wenquanbingzhan area. The fractures of Yanshiping and Wenquanbingzhan area etc. are the big fractures of guide rock and rock-controlled and the fracture zones in the northwest of Chuduo-Chaqiong play an ore conducting and controlling role in the process. The metallogenic condition of anticline structure is better than that of syncline structure. Based on the above consideration, the diagenesis and mineralization in this area are closely related to the intermediate-basic and acidic magmas activity. Copper and polymetallic ores can be classified to volcanics-type and sedimentary-reformed type.
\end{abstract}

Keywords: Wenquanbingzhan Study Area, Metallogenic Condition, Geochemical Analysis, Factor Metering, Medium Acid Volcanic Rocks, Metallogenic Structure

\section{Introduction}

Wenquanbingzhan area is located in the middle of Qinghai-Tibet Platean and lies to the north of Tanggula Mountains, where is chillness and oxygen shortage. The natural condition is so bad that less geological field works are put into effect. From 1980s to 2005, a lot of geological works had been carried out in this area such as 1: 250000 regional geological exploration, 1: 200000 regional geochemical exploration and comprehensive research work on mineralization prospects. According to the above works, it had been identified the regional stratigraphic lithology, lithofacies, thickness variations and the regional distribution characteristics and regularities of 40 elements. The first-level structural unit was divided based on the comprehensive study on rock mass, lithofacies, rock association and the contact relation with surrounding rock in this area. This study area was be attributed to the III-level metallogenic belt-Yan shi ping iron, lead, zinc, crystal and gypsum metallogenic belt. It was considered that the minerals with the greatest and most sure hope for mineralization are $\mathrm{W}, \mathrm{Bi}, \mathrm{Au}, \mathrm{Hg}, \mathrm{Sn}, \mathrm{Mo}, \mathrm{As}$,
$\mathrm{Pb}, \mathrm{Sb}$, etc. The type of deposit was mainly marine volcanic rock type, with the small Tanggula iron-lead ore as the typical representative, followed by contact contact metasomatism, hydrothermal and sedimentary type. From 2012 to 2016, the total area of 1: 50000 stream sediment survey has been to 2416 $\mathrm{km}^{2}$ and 11035 drainage sediment samples have been quantitative determinated out $\mathrm{Cu}, \mathrm{Pb}, \mathrm{Zn}, \mathrm{Ag}, \mathrm{Cd}, \mathrm{Au}, \mathrm{As}, \mathrm{Sb}$, $\mathrm{Hg}, \mathrm{Ba}, \mathrm{W}, \mathrm{Sn}, \mathrm{Mo}, \mathrm{Bi}, \mathrm{Cr}, \mathrm{Ni}, \mathrm{Co}, \mathrm{V}, \mathrm{Ti}, \mathrm{Mn}$. Geological prospecting has been done in the important abnormity with the spectrum analysis on 100 core samples of ZK02. The author introduces a subject on metallogenic basic geology geochemical analysis in the 1: 50000 geochemical exploration.

\section{Geological Background}

\subsection{Geotectonic Location and Metallogenic Belt}

Wenquanbingzhan is located in the north of Qiangtang block, which is between Lazhulong-Jinshajiang River suture zone and Bangongcuo-Nujiang River suture zone (Figure 1). 
It is also located to the north of Sanjiang metallogenic belt, being part of the iron, lead, zinc (bismuth, tin, antimony)

crystal, gypsum Yanshiping metallogenic belt in Yanshan period $\left(\mathrm{III}_{25}\right)[1]$.

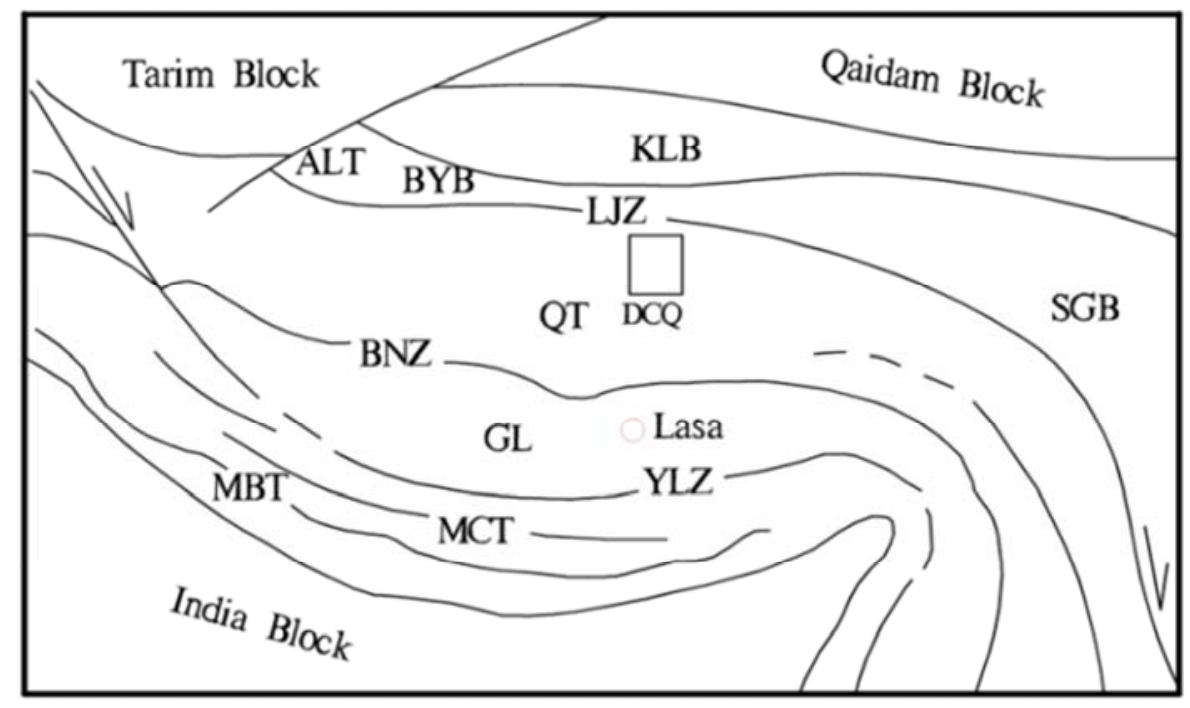

Figure 1. The tectonic position map of the study area.

MBT - Himalaya marginal fault; MCT - Himalaya central fault; KLB - Kunlun tectonic belt; SGB - SongPang - Ganzi tectonic belt; QT - Qiangtang block; GL-Gangdise block; BNZ - Bangongcuo - Nujiang suture zone; LJZ - Lazhuong - Jinshajiang suture zone; YLZ - Yalu Tsanppo river suture zone; DCQ Wenquanbingzhan study area.

\subsection{Stratum, Tectonic and Magmatic Rock}

The study area lies at Tuotuo River area which is located in the west of "Sanjiang north section" (Generally refers to basin deposition from the Tanggula Mountain to Tuotuo River in Mesozoic and Cenozoic (Song Yucai etc., 2012) [2-4], sedimentary rock and little volcanics which have grown from Permian are part of Danggula-Changdu layer, according to the Stratigraphic scheme in «Lithostratigraphy of Qinghai Province" (1997) published by Qinghai Geology and mineral resources Bureau. Its Exposure strata are Ninety teams of Permian $\left(\mathrm{P}_{2} j\right)$, The upper Triassic Perera formation $\left(\mathrm{T}_{3} b\right)$, bagong formation $\left(\mathrm{T}_{3} b g\right)$, Jurassic sparrow formation $\left(\mathrm{J}_{2} q\right)$, Buqu formation $\left(\mathrm{J}_{2} b\right)$, Xia $\mathrm{Li}$ formation $\left(\mathrm{J}_{2} x\right)$, Suowa Formation $\left(\mathrm{J}_{3} s\right)$, Cretaceous Cuojuri Formation $\left(\mathrm{K}_{1} c\right)$, Paleogene Tuotuo river Formation $\left(\mathrm{E}_{1-2} t\right)$ and so on, among which the most widely distributed stratigraphic unit is the Middle upper Jurassic. The Quaternary is mainly distributed in the north and the genetic types include the Pleistocene ground-sliding accumulation, glacial-ice water accumulation and Holocene marsh accumulation, alluvial accumulation and alluvial.

According to the available geological information, the lithology of the Jiushidaoban Formation is dominated by limestone with a small amount of basalt. And the remaining strata are sandstone and limestone. Only the Quemocuo formation is sporadic basalt and coarse basalt. From above, the Quemocuo formation is composed of fossils of plant fragments and marine and non-marine bivalves. The Xiali group has bivalves, brachiopods, algae, silicified wood and other fossils [6].

The intra region structure is well-developed, mainly including Kendima Fault (F1, the boundary between the
Kailing uplift and the Qiangtang basin), Yanshiping fault $\left(\mathrm{F}_{2}\right)$, Burong fault $\left(\mathrm{F}_{3}\right)$, Chdo - chqiong North westward fault $\left(\mathrm{F}_{4}\right.$, $\left.F_{5}\right)$, Wenquanbingzhan fault $\left(F_{6}\right)$, North-South fault $\left(F_{7}\right)$, NE trending fault $\left(\mathrm{F}_{8}\right)$ and Wenquanbingzhan anticline, Yanshiping syncline, Burong syncline (Figure 2).

\subsection{Mineral}

There are 32 different types of mineralization and mineralization trails in this area [6-8]. Among those points, there is 1 medium iron lead mineralization point, 8 iron mineralization points, 1 siderite mineralization point, 3 copper mineralization points, 3 Copper silver mineralization points, 1 polymetallic mineralization point, 2 zinc mineralization points, 1 lead mineralization point, 1 placer gold mineralization point, 2 barite mineralization points, 4 gypsum ore points and 5 gypsum mineralization points. Various types of Mines in this area are evidently controlled by the North West fault structure. Meanwhile, they are also influenced by the lithologies in different stratums, the hydrothermal mineralization points are related to the magmatic activity.

\section{Element Combination Characteristics and Their Geological Significance}

\section{1. $R$ clustering Analysis}

The analysis results of stream sediment samples in this area are analysed by R clustering analysis (Figure 3), 20 elements are obviously divided into 4 ethnic groups. 


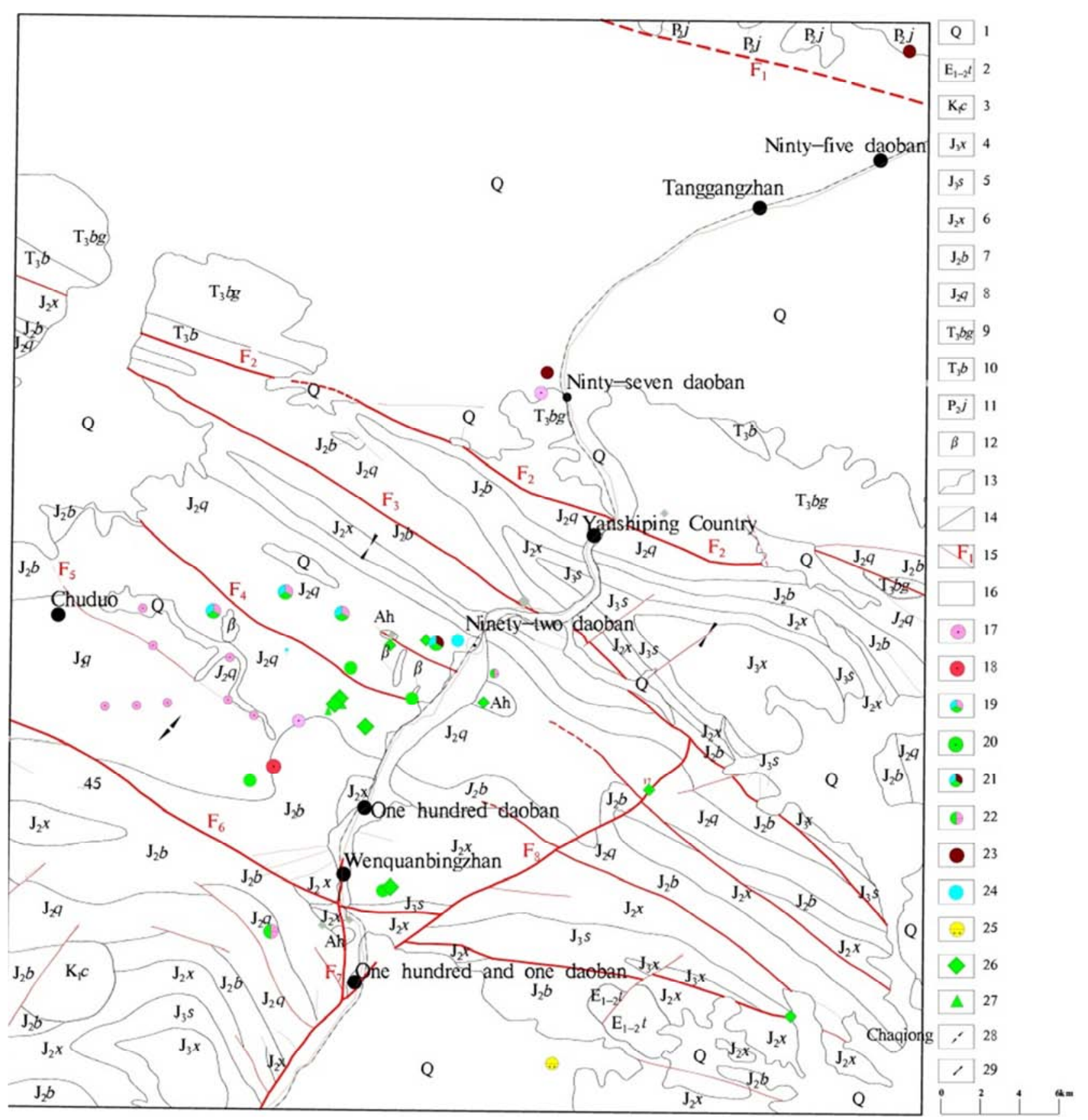

Figure 2. Geological and mineral distribution map of Yanshiping area.

Quaternary

Tuotuohe formation

Cuojuri formation

Xueshan formation.

Suowa formation

Xiali formation

Buqu formation

Quemocuo formation.

Bagong formation

Bolila formation

Ninety daoban formation

Basalt.

Stratigraphic boundary

Unconformity boundary

Fault and its number.
Lead-Zinc deposit

Iron mineralized spot

Siderite mineralized spot.

Copper-lead-sliver Polymetallic mineral occurrence

Copper mineralized spot.

Polymetallic mineral occurrence

Copper -sliver mineral occurrence.

Znic mineralized spot

Lead mineralized spot

Gulch-gold mineralized spot.

Gypsum mineralized spot

Barite mineralized spot

Anticline

Syncline. 


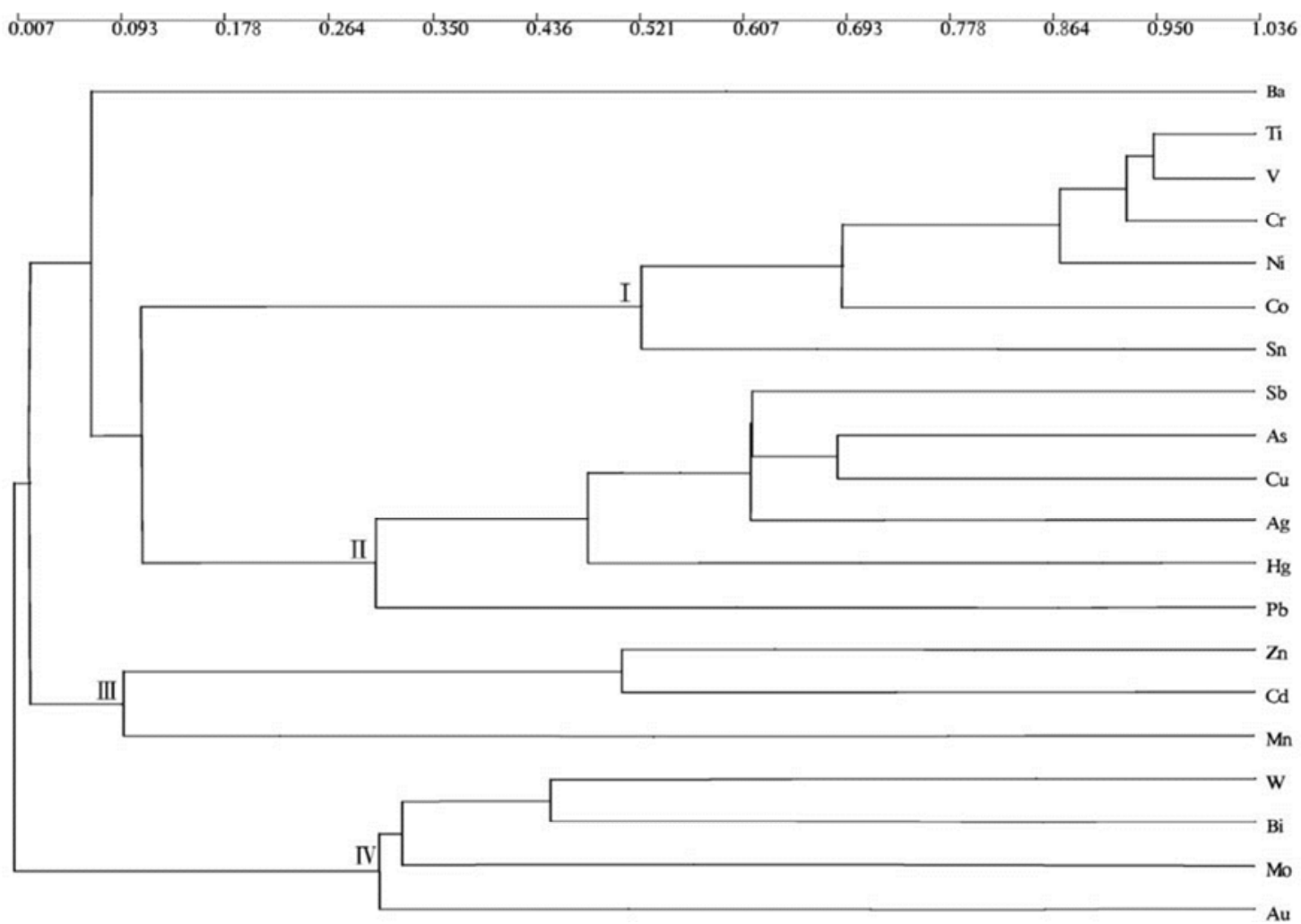

Figure 3. Stream sediment 20 elements R-type cluster analysis pedigree chart in Yanshiping area.

The I cluster is a combination of Cr-Ni-Co-V-Ti-Sn, reflecting the characteristics of the medium-basic rock in the area.

The II cluster is a combination of $\mathrm{Sb}-\mathrm{As}-\mathrm{Cu}-\mathrm{Ag}-\mathrm{Hg}-\mathrm{Pb}$ combination, reflecting the medium-low temperature hydrothermal copper-silver mineralization associated with fault activity in the area.

The III cluster is a combination of $\mathrm{Zn}-\mathrm{Cd}-\mathrm{Mn}$, reflecting features of the sedimentary hydrothermal transformation of zinc cadmium polymetallic mineralization here.

The IV cluster is a combination of $\mathrm{W}-\mathrm{Bi}-\mathrm{Mo}-\mathrm{Au}$, reacting features of the intermediate acid rock mass contact zone and high temperature hydrothermal mineralization here.

\subsection{Factor Analysis}

The factor analysis of 20 elements is shown in Table 1 . The F1 and F3 factors reflect the most representative characteristics of the ore-forming conditions in the Wenquanbingzhan. Therefore, the twiddle factor F1 and F3 measurement charts are produced, as shown in Figure 4 and Figure 5.

Table 1. Twiddle factor feature table in Yanshiping area.

\begin{tabular}{|c|c|c|c|c|}
\hline Factor & $\begin{array}{l}\text { Characteris } \\
\text { tic root }\end{array}$ & $\begin{array}{l}\text { Characterist in } \\
\text { root percentage } / \%\end{array}$ & Main load elements and their load values & Geological and Geochemical Significance \\
\hline F1 & 4.849 & 24.244 & $\begin{array}{l}\text { Ti0.966, V0.955, Cr0.946, Ni0.936, Co0.789, Sn0.548, } \\
\text { Au0.201, Bi0.113, Sb0.095, Zn0.082 }\end{array}$ & $\begin{array}{l}\text { Intermediate basic volcanic rocks and } \\
\text { subvolcanic rocks }\end{array}$ \\
\hline $\mathrm{F} 2$ & 3.210 & 16.051 & $\begin{array}{l}\mathrm{Cu} 0.919, \mathrm{As} 0.877, \mathrm{Sb} 0.717, \mathrm{Ag} 0.356, \mathrm{Mo} 0.141 \\
\mathrm{Cd} 0.115, \mathrm{~Pb} 0.101\end{array}$ & $\begin{array}{l}\text { Hydrothermal copper polymetallic } \\
\text { mineralization }\end{array}$ \\
\hline F3 & 1.771 & 8.855 & $\begin{array}{l}\text { Bi0.914, W0.732, Au0.205, Mo0.172, Sn0.085, } \\
\text { Ag0.069 }\end{array}$ & $\begin{array}{l}\text { Contact alteration mineralization of } \\
\text { intermediate acid rock mass }\end{array}$ \\
\hline $\mathrm{F} 4$ & 1.623 & 8.116 & $\begin{array}{l}\mathrm{Zn} 0.886, \mathrm{Cd} 0.817, \mathrm{~Pb} 0.204, \mathrm{Mo} 0.193 \text {, As0.117, } \\
\mathrm{Co} 0.09\end{array}$ & $\begin{array}{l}\text { Sedimentary hydrothermal transformation of } \\
\text { zinc polymetallic mineralization }\end{array}$ \\
\hline F5 & 1.244 & 6.221 & $\begin{array}{l}\text { Mn0.912, Co0.448, Mo0.369, Ni0.174, As0.092, } \\
\text { Ag0.058 }\end{array}$ & $\begin{array}{l}\text { Mineralization related to marine volcanic } \\
\text { rocks }\end{array}$ \\
\hline F6 & 1.142 & 5.711 & $\mathrm{Hg} 0.955, \mathrm{Sb} 0.501, \mathrm{Ag} 0.42, \mathrm{Bi} 0.041$ & $\begin{array}{l}\text { Low temperature hydrothermal mercury } \\
\text { antimony mineralization in fault zone }\end{array}$ \\
\hline F7 & 0.959 & 4.793 & $\mathrm{Ba} 0.996, \mathrm{Ag} 0.061$ & Low temperature barite mineralization \\
\hline F8 & 0.829 & 4.146 & $\mathrm{~Pb} 0.91, \mathrm{Ag} 0.662, \mathrm{Sb} 0.263, \mathrm{Cd} 0.23, \mathrm{As} 0.106, \mathrm{Hg} 0.068$ & $\begin{array}{l}\text { Middle and low temperature hydrothermal } \\
\text { lead silver polymetallic mineralization }\end{array}$ \\
\hline F9 & 0.771 & 3.854 & Mo0.736 Sn0.581, W0.36, As0.128, Mn0.095 & $\begin{array}{l}\text { Contact alteration zone of intermediate acid } \\
\text { rock mass }\end{array}$ \\
\hline F10 & 0.705 & 3.525 & Mo0.12, W0.21, Au0.94 & $\begin{array}{l}\text { Gold mineralization in contact zone of } \\
\text { intermediate acid rock mass }\end{array}$ \\
\hline
\end{tabular}


The F1 factor is characterized by the combination of iron group $\mathrm{Cr}-\mathrm{Ni}-\mathrm{Co}-\mathrm{V}-\mathrm{Ti}-\mathrm{Sn}$ and is closely related to the I cluster element combination of R-type cluster analysis, which is related to the medium-basic magmatic activity.

The F2, F6 and F8 factors are characterized by copper polymetallic, mercury-niobium polymetallic and lead-polymetallic combinations, respectively corresponding to the combination of Group II elements of R-type cluster analysis, which are different types of hydrothermal polymetallic mineralization in the region.

The $\mathrm{F}_{4}$ factor is charactered by zinc cadmium polymetallic combination, which corresponds to the combination of the group III elements of the R-type cluster analysis, and is a reflection of the deposition of hydrothermal reformation of zinc polymetallic mineralization in the region.

The F5 factor is characterized by a combination of manganese, cobalt, molybdenum, nickel, arsenic and silver, which is presumed to be related to marine volcanic rocks and their mineralization.

The F7 factor is characterized by barium, which is consists with the last number of $\mathrm{R}$ clustering analysis on barium only, and is a reflection of the low-temperature hydrothermal fissure-filled barite mineralization in the zone.

The F3, F9 and F10 factors are characterized by a combination of tungsten, antimony, gold and arsenic, which correspond to the combination of Group IV elements of R-type cluster analysis, and are a reflection of the medium-acid intrusive rock contact zone and high-temperature hydrothermal mineralization.

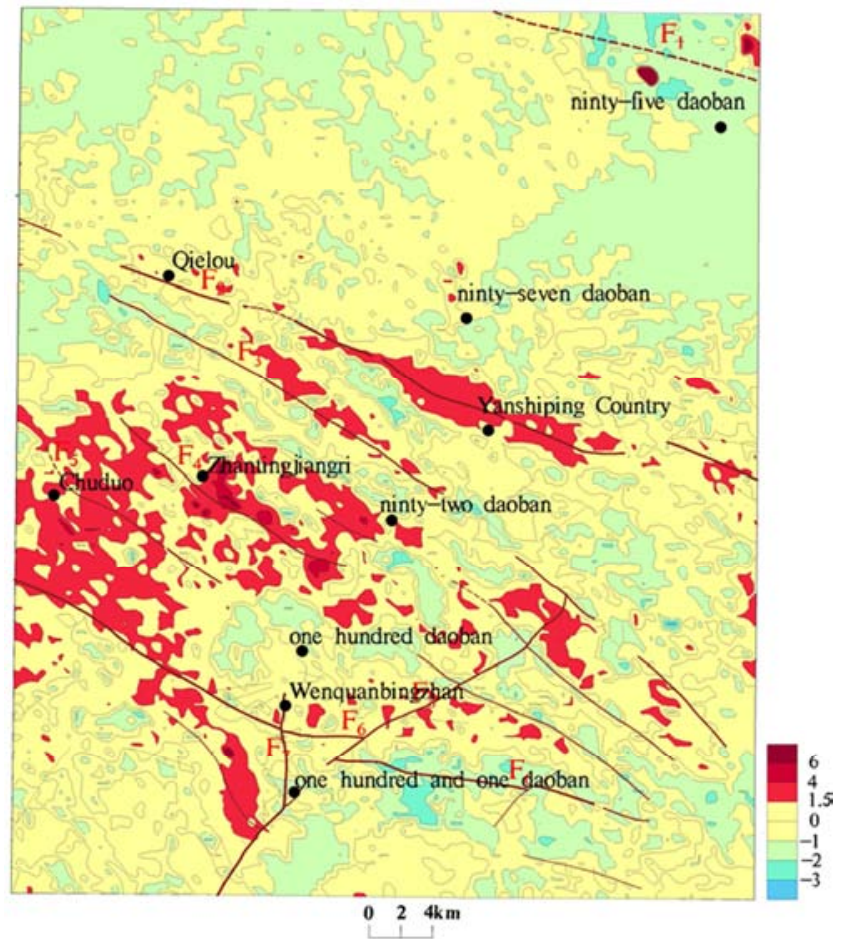

$\mathrm{F}_{1}$ : Ti0.966, V0.955, Cr0.946, Ni0.936, Co0.789, Sn0.548.

Figure 4. Anomaly distribution graph of $F_{1}$ factor measurement in Wenquanbingzhan area.
According to the $F_{1}$ factor measurement figure (Figure 4), the known allgovite, basalt, trachybasalt, andesite in Wenquanbingzhan area showed by the equivalent line value $\geq 1.5$, are fitted closely with the Iron elements such as $\mathrm{Cr}, \mathrm{Ni}$, $\mathrm{Co}, \mathrm{V}, \mathrm{Ti}$, and the equivalent line value $\geq 1.5$ can be considered as the superposition of high background and abnormity, reacting intermediate basic magmatic rocks (giving the first place to volcanic rock, subvolcanic rock).

Information of presentation for the red area in $F_{1}$ factor measurement figure:

Intermediate basic volcanic rocks in Wenquanbingzhan is not only the local scattered and small scale distribution in geological map (Figure 2), there is distribution of large scale intermediate basic volcanic rocks in belts, patches and zones in central southern Chu do - Yanshiping-Wenquanbingzhan area.

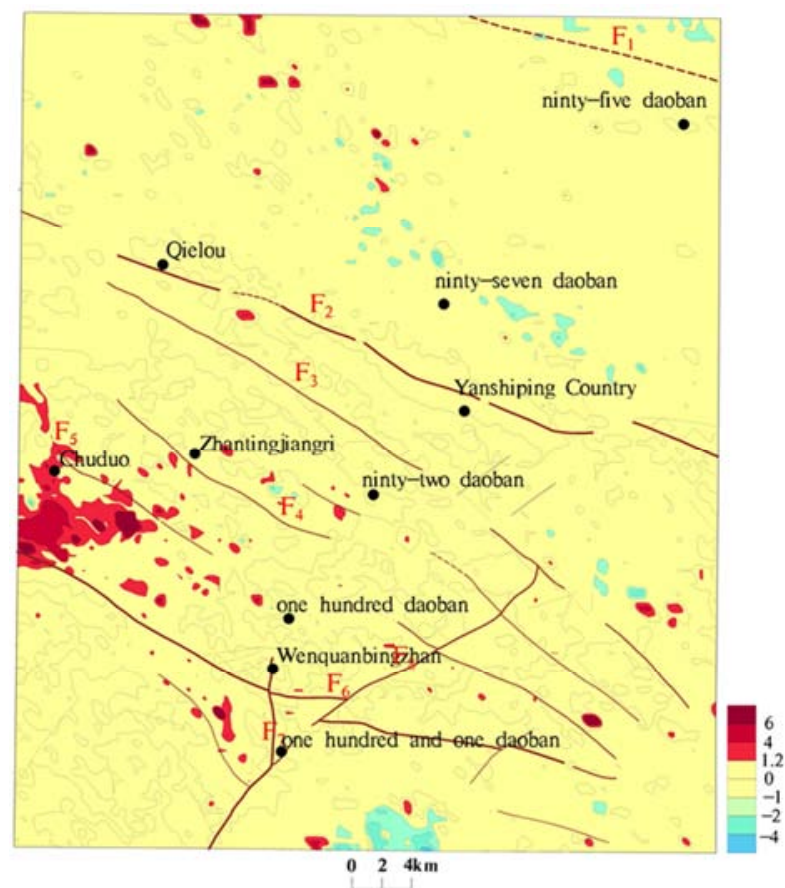

$\mathrm{F}_{3}$ : Bi0.914, W0.732, Au0.205, Mo0.172, Sn0.085.

Figure 5. Anomaly distribution graph of $F_{3}$ factor score graph in Wenquanbingzhan area.

Intermediate basic volcanic rocks in belts, patches and zones distribute along Yanshiping-Geima fault, Buchan fault, Wenquanbingzhan fault, north-south fault and Chuduo-Chaqiong NW fault zone, illustrating clearly that those faults are mainly deeper faults in rock and rock control, volcanism can be mainly fissure injection.

In $\mathrm{F}_{3}$ factor measurement chart (Figure 5), the equivalent line value $\geq 1.2$ area concludes both the sections of feldspar porphyry, plagiogranite porphyry, porphyrite diorite vein, granite aplite vein in Chuduo-Shanalongren area and the section of granite, monzonite in Tangjina-Dandequ area which match $\mathrm{W}, \mathrm{Bi}, \mathrm{Mo}, \mathrm{Sn}, \mathrm{Au}$ abnormal area showing the mineralization of the alteration zone of intermediate acid intrusive rocks or high temperature hydrothermal W, Bi and Au. 
Information of presentation for the red area in $\mathrm{F}_{3}$ factor measurement figure:

1) There may be a large burial medium-acid concealed rock mass in the lot, and the contact alteration zone has been partially exposed in Cuduo-Shanalongren section and Yanshiping area.

2) There may be a small distribution of medium-acid rock mass in the southwest of Yanshiping area.

3) There may be large-scale medium-acid intrusive rocks in
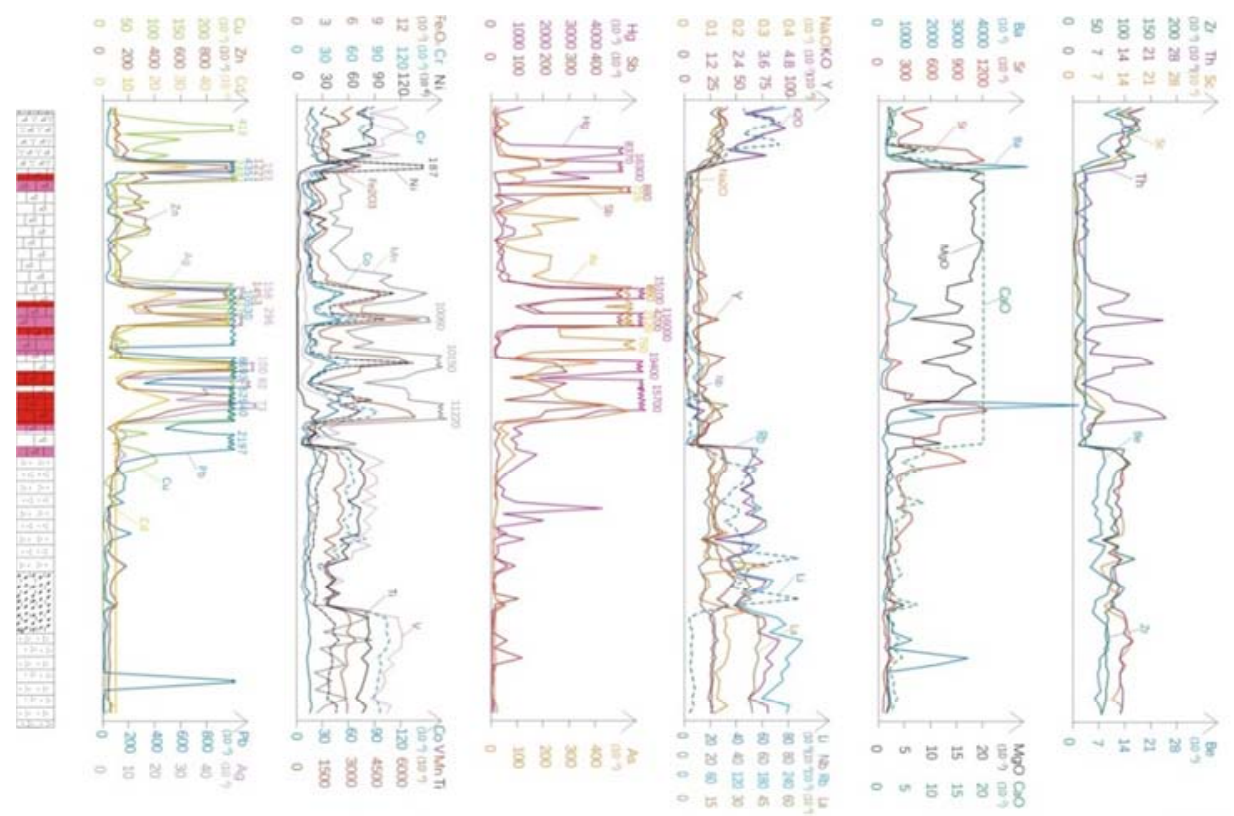

the north-central part of the area.

\subsection{Geochemical Characteristics of Rocks (Ores)}

On the basis of the full analysis of borehole core-like spectra, a comprehensive map of geological geochemical character corresponding to 35 element content curves and borehole histograms was made. R-type cluster analysis was performed on 35 elements of 100 bedrock samples.

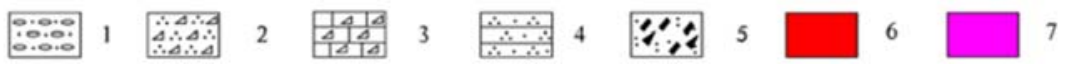

Figure 6. Geochemical map of Cr. Ni. Co. V. Ti elements and anomaly map of iron group elements.

1-Eluvium 2-Cataclastic Sandstone 3-Cataclastic Limestone 4-Sandstone 5-Andesitic crystal-debris tuff 6-Gold polymetallic ore bodies 7- Sliver polymetallic ore bodies.
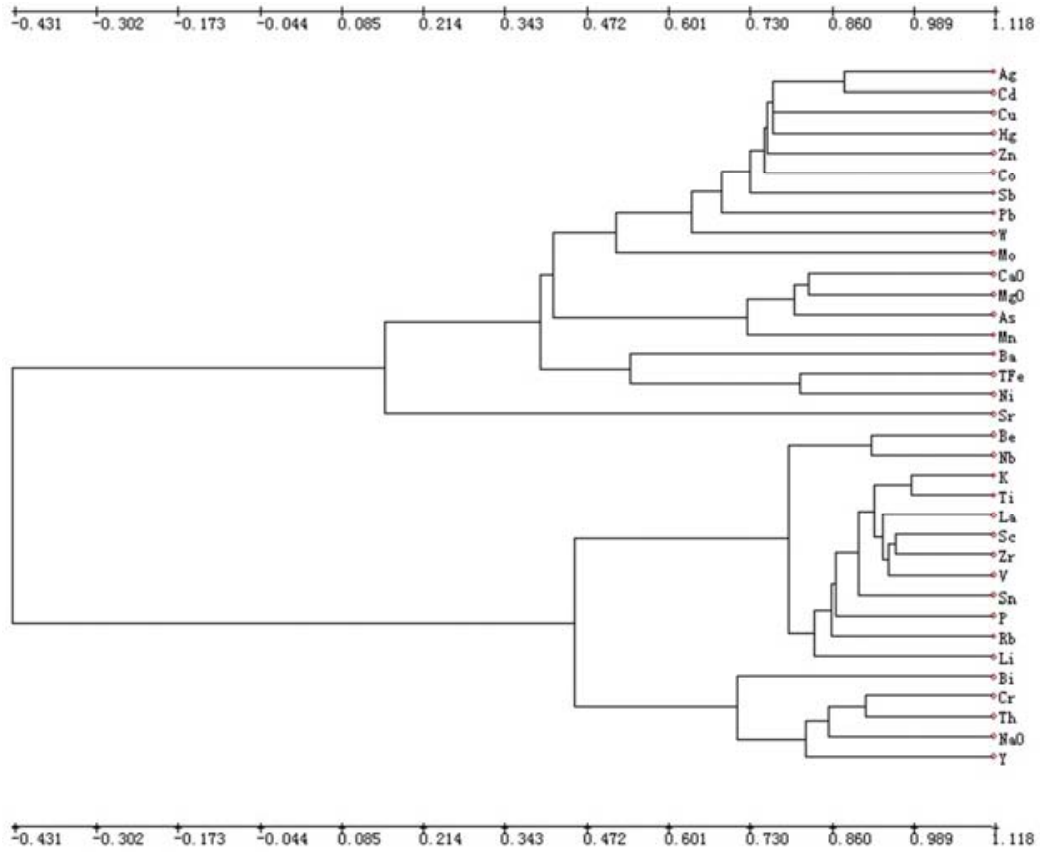

Figure 7. Rock 35 elements R-type cluster analysis pedigree chart of the ZK02 drilling from copper-sliver polymetallic ores in Wenquanbingzhan area. 
It can be clearly seen from figure 6 that the strong anomalies of $\mathrm{Cu}, \mathrm{Pb}, \mathrm{Zn}, \mathrm{Ag}$ and $\mathrm{Cd}$ are caused by copper-silver polymetallic ore, and closely correspond to the high background or anomaly of $\mathrm{Cr}, \mathrm{Ni}, \mathrm{Co}, \mathrm{V}, \mathrm{Ti}, \mathrm{Mn}$ and $\mathrm{Fe}$. Associated with strong anomalies of $\mathrm{As}, \mathrm{Sb}$ and $\mathrm{Hg}$, the combination is located in the fractured limestone, which the content of $\mathrm{Y}, \mathrm{Na}_{2} \mathrm{O}, \mathrm{K}_{2} \mathrm{O}$, La, Li, Nb, Rb, Ba, Sr, Zr, Sc, Be, Sn, $\mathrm{Bi}$ in limestone is lower than in sandstone and tuff. Compared with sandstone and tuff, the content of iron group is significantly higher than that of sandstone and tuff. There is a strong narrow $\mathrm{Ba}$ anomaly near copper-silver polymetallic ore body, and Th, W, Mo and Sn anomalies occur locally.

35 elements are obviously divided into two groups according to figure 7 :

Group I, characterized by the combination of $\mathrm{Ag}-\mathrm{Cd}-\mathrm{Cu}-\mathrm{Hg}-\mathrm{Zn}-\mathrm{Co}-\mathrm{Sb}-\mathrm{Pb}, \quad \mathrm{CaO}-\mathrm{MgO}-\mathrm{As}-\mathrm{Mn}$ and $\mathrm{Ba}-\mathrm{TFe}-\mathrm{Ni}$, reflects the medium-low temperature hydrothermal copper and silver polymetallic mineralization associated with the fracture activity, as well as continental margin-shallow sea sedimentary metallogenic background and volcanic and subvolcanic ore-forming systems. It can be considered that the combination of $\mathrm{CaO}-\mathrm{MgO}-\mathrm{As}-\mathrm{Mn}$ and $\mathrm{Ba}-\mathrm{TFe}-\mathrm{Ni}$ reflects the volcanic-sedimentary rock combination characteristics, and the Quemoq group has volcanic clastic rock components and terrigenous clastic components. The iron group elements in the fractured limestone are significantly higher than the sandstone and tuff, indicating that the volcanic clastic rocks in the lithologic section are mainly composed of medium base. The volcanic rocks and subvolcanic rocks are important ore-forming geological bodies of copper and silver in this area.

Group II shows characteristics of terrigenous clasts elements combination, being corresponding to cataclastic sandstone, calcareous sandstone, lithic sandstone and siltstone in figure 6 .

The above characteristics indicate that the copper-silver polymetallic ore is closely related to the fragmented limestone. Along the regional deep fault with the medium-basic magmatic hydrothermal activity, the iron group elements are more developed in the limestone fracture zone, and the medium-basic volcanic rocks. It is likely to provide a major material basis for multi-metal mineralization such as copper, silver, lead, etc. The associated $\mathrm{As}, \mathrm{Sb}, \mathrm{Hg}$, and $\mathrm{Ba}$ anomalies further indicate that the mineralization is dominated by medium-low temperature hydrothermal fluids. High background or weak anomaly of $\mathrm{W}, \mathrm{Mo}, \mathrm{Sn}, \mathrm{Th}$, indicate that there may be geological effects related to the medium-acid magmatic hydrothermal fluid.

\section{Metallogenic Geological Analysis}

\subsection{Intermediate Basic Volcanic Rocks}

The $\mathrm{R}$ cluster analysis and factor analysis showing that there is Cr-Ni-Co-V-Ti iron element combination in Wenquanbingzhan area. This combination indicates its significance and stability which is the first group of elements in this area.

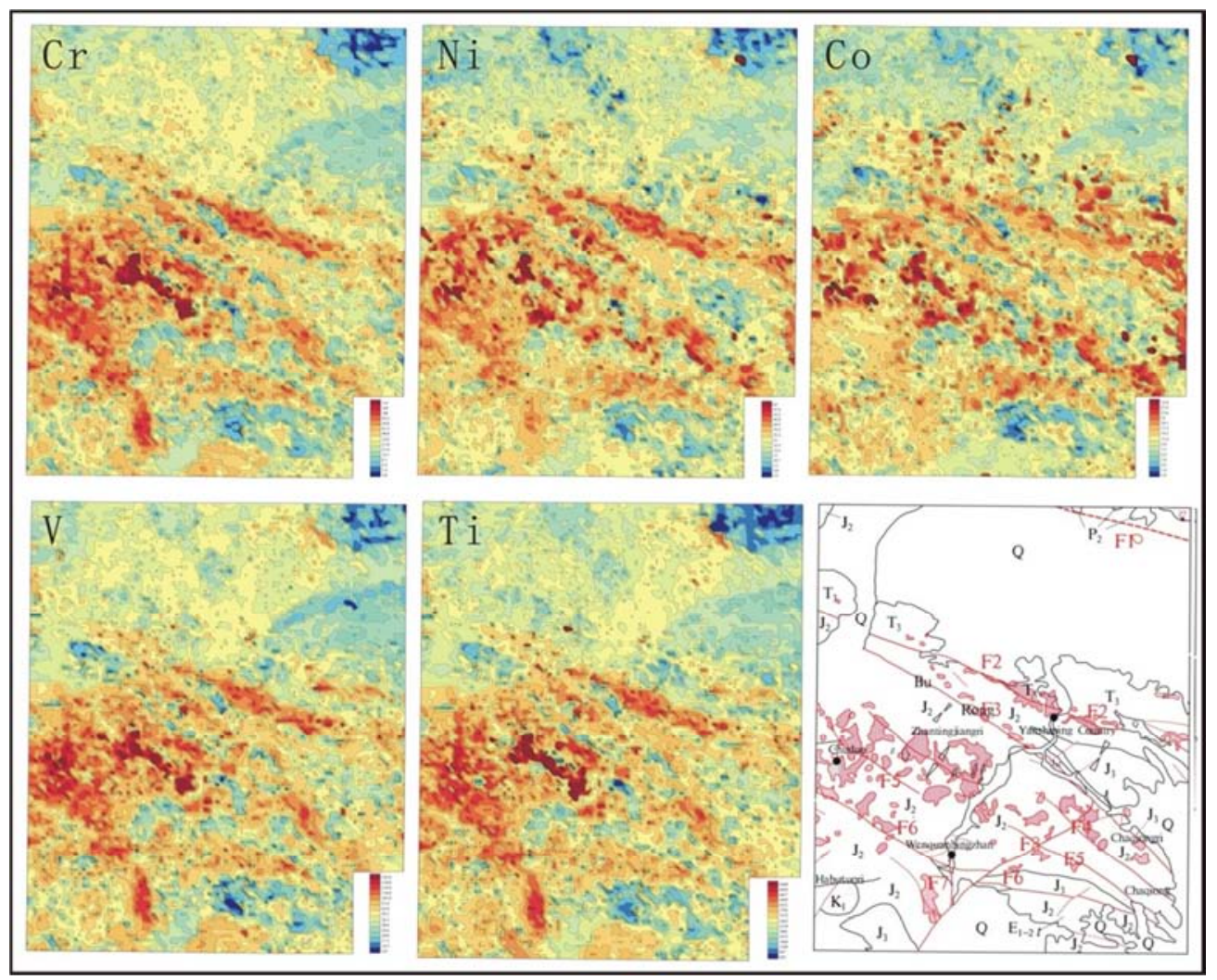

Figure 8. Geochemical distribution of chromium-nickel-cobalt-vanadium and the comprehensive distribution of iron-group elements in the Wenquanbingzhan area. 
It can be seen from Figure 8 that the high background and anomalies of $\mathrm{Cr}, \mathrm{Ni}, \mathrm{Co}, \mathrm{V}$ and $\mathrm{Ti}$ in the region are very significant which is large and closely coincide with each other. All that indicate there is obviously a Cr-Ni-Co-V-Ti element formed in the region which means the powerful geological role of the combination.

According to general geology and geochemistry knowledge, this combination is related to intermediate and ultrabasic magmatic activities [9-13]. The content of $\mathrm{Cr}, \mathrm{Ni}, \mathrm{Co}$ in ultrabasic rock are more than ten times in this area. According to the existed geology geochemistry knowledge here, this iron element combination reacts intermediate basic volcanic rocks (including subvolcanic rocks) and the red region in $\mathrm{F}_{1}$ factor measurement chart (Figure 4) is the intermediate basic volcanic rock section.

Consequently in the central and southern parts of Chuduo-Yanshiping-Wenquanbingzhan, there can be distribution of large scale intermediate basic volcanic rocks in belt, patch and zone. It is far different with the situation at present in regional geological map. There may be many reasons that the main reason maybe that some of the basic volcanic rocks disappeared in the sedimentary strata and less attention has been paid to this work in the past. In recent years, the geochemical anomaly inspection and geological work in this area have continuously found diabase porphyrite, basalt andesite of a certain scale, which can explain this point to some extent. This will be verified in further field work.

Because of the large-scale distribution of intermediate-basic volcanic rocks in the area, it is reasonable to explain why the formation of volcanic-type medium-sized $\mathrm{Fe}-\mathrm{Pb}$ deposits occurs and why there are many volcanic-type iron ore deposits (chemical) points in the area.

\subsection{Intermediate Acid Intrusive Rocks}

The R-type cluster analysis and factor analysis show that there are obvious W-Sn-Bi-Mo-As-Au high-temperature hydrothermal elements assemblages in the area, and the composition of the elements assemblages is not uniform in different sections. But the main elements are high temperature hydrothermal elements, such as W, Sn, Bi, Mo and As.

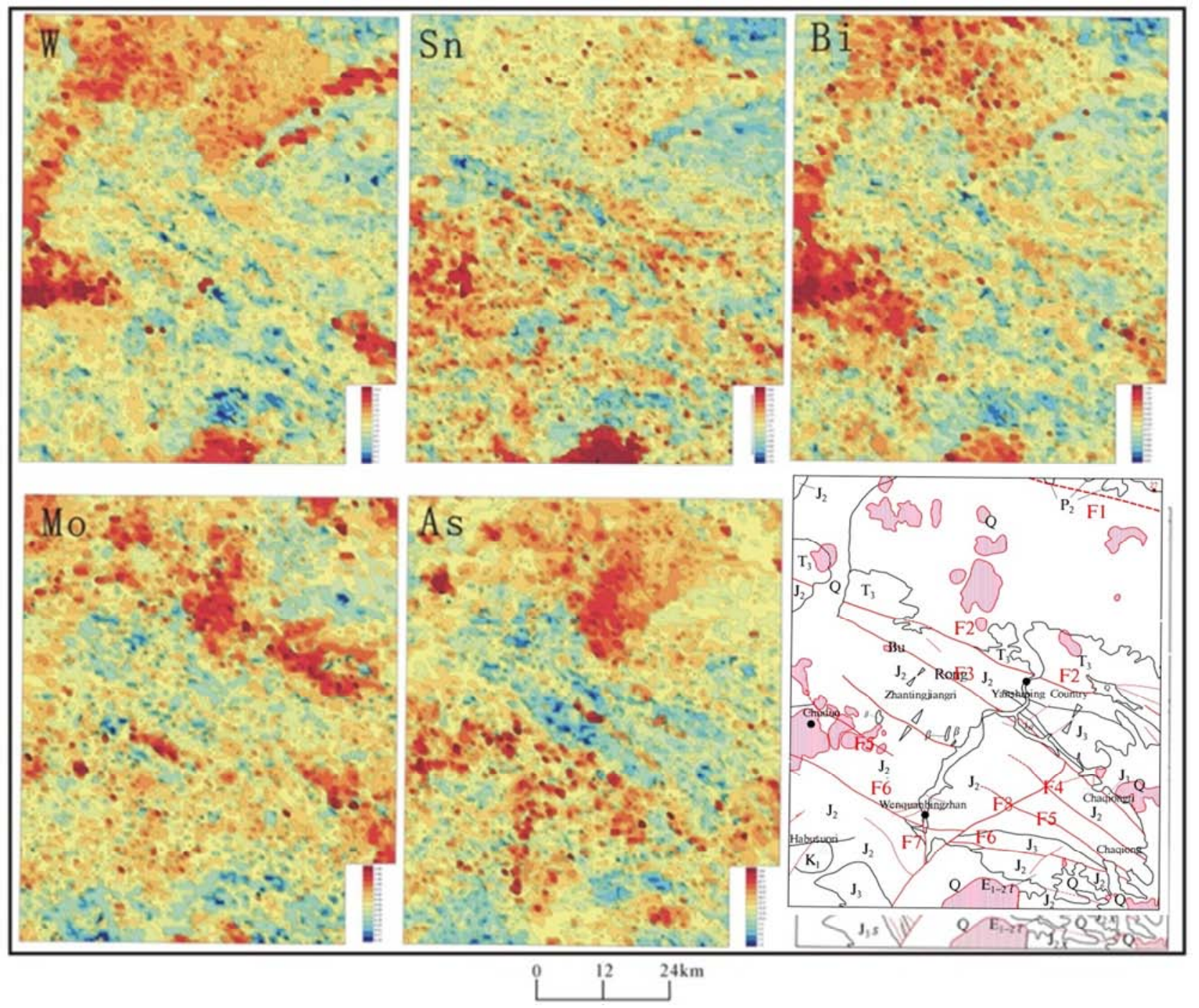

Figure 9. Geochemical map of Wo. Sn. Bi. Mo. As elements and anomaly map of hypothermal elements. 
It can be seen from Figure 9 that the elements of $\mathrm{W}, \mathrm{Sn}, \mathrm{Bi}$, $\mathrm{Mo}, \mathrm{As}, \mathrm{Au}$, etc. have obvious high background and anomalies in the film. W and $\mathrm{Bi}$ are in good agreement. Sn is partially consistent with it. Mo and As are complementary appear. There is a clear geological effect of forming a combination of high temperature hydrothermal elements in this area.

According to the general geological-geochemical knowledge, W, Bi, Sn and Mo are closely paragenesis and are usually related to the diagenesis and mineralization of intermediate-acid magma [9-13]. The aeromagnetic anomalies in the distribution area of the MuNai monzonitic granite body in Figure 10 are consistent with the Xiaotanggula mining area in Chuduo area. Accordance with the known geological and geochemical characteristics in the region, it is considered that the high temperature hydrothermal element assemblage is related to the contact alteration mineralization zone of intermediate-acid intrusive rocks. The red area in the F3 factor diagram (Figure 5) should be the distribution area of intermediate-acid intrusive rocks and their contact alteration zones. There may be a certain scale of concealed intermediate-acid intrusive rocks in Chuduo area whose contact alteration zone has been partly exposed. The distribution of syenite porphyry dike [7], granite fine-grained dike, quartz syenite dike and quartz dike [1] has been found in this area by predecessors, which also proves the existence of intermediate-acid magmatic activity in this area.

From Figure 9, it can be seen that there is a remarkable Mo anomaly area in the eastern part of the survey area. There is no obvious $\mathrm{W}, \mathrm{Bi}, \mathrm{As}$ anomaly in this area, but a comprehensive study found that there are other $\mathrm{Cu}, \mathrm{Mn}$ anomalies accompanied by $\mathrm{Cu}-\mathrm{Pb}-\mathrm{Ag}$ anomaly around the periphery. It is speculated that this area may have porphyry copper-molybdenum mineralization, which is worthy of further study and verification.

It can be seen from figure 8 , figure 9 and the factor analysis results that the distribution of $\mathrm{Sn}$ in the measurement area has a certain relationship with $\mathrm{W}, \mathrm{Mo}$ and $\mathrm{Bi}$, and it is obvious that there are iron elements such as $\mathrm{Ti}, \mathrm{V}, \mathrm{Cr}, \mathrm{Ni}$ and $\mathrm{Co}$. The relationship with the growth and decline indicates that the $\mathrm{Sn}$ in the survey area participates in the high-temperature hydrothermal action related to the medium-acid magma, and also participates in the diagenesis related to the basic magma
[14-18]. It indicates that there is a strong crust-mantle magma role inWenquanbingzhan area.

\subsection{Tectonics}

Figures 4 and 8 reflect the fact that volcanic rocks are distributed along fault zones, which, in turn, indicates that Yanshiping fault (F2), Buchan fault (F3), Wenquanbingzhan fault (F6), north-south fault (F7) and Chuduo-Chaqiong NW fault zone (F4, F5) are the deeper faults of conducting and controlling rocks and that volcanic activity may be dominated by fissure eruption.

Figure 2 shows clearly that the NW trending faults (F3, F4, F5, F6) and NNE trending fault (F8) hold the core of the anticline at Wenquanbingzhan, and a large number of $\mathrm{NW}$ trending secondary faults are developed. Many $\mathrm{Fe}, \mathrm{Cu}, \mathrm{Ag}$, polymetallic ore spots and mineralization spots are distributed along the F4 and F5 fault zones, while the Yanshiping syncline and the cloth slanting syncline have only scattered copper mineralization points and gypsum deposits. The fault zone (represented by F4 and F5) is a fault zone for ore-bearing and ore-controlling, and the anticline structure is better than the syncline structure. The distribution of gypsum deposits shows that the northwest fault zone of Chuduo-Chaqiong (represented by F4 and F5) is a fault zone of ore-conducting and ore-controlling, and the metallogenesis of anticline structure is superior to syncline structure.

\subsection{Minerals}

The common metal minerals in this area are siderite, specularite, hematite, limonite, galena, white lead, siderite, malachite, blue copper, copper blue, porphyry copper, chalcopyrite, sphalerite and so on. According to the metallogenic geology and geochemical characteristics of the existing ore spots and mineralization points, the area can be divided into six basic metallogenic types, namely, high-temperature hydrothermal, medium-temperature hydrothermal, low-temperature hydrothermal, sedimentary, sedimentary hydrothermal reformation, volcanic rocks. [8, 19-20] The related ore types, main metallogenic characteristics and element assemblage characteristics of each type are shown in Table 2.

Table 2. Geological and geochemical feature table of main metallogenic type deposits.

\begin{tabular}{|c|c|c|c|}
\hline Metallogenic type & Related ore spots and minerals & Metallogenic characteristics & Element combination characteristics \\
\hline $\begin{array}{l}\text { High temperature } \\
\text { type }\end{array}$ & $\begin{array}{l}29 \text { B } 1 \text { abnormal tungsten } \\
\text { mineralization }\end{array}$ & $\begin{array}{l}\text { Tungsten mineralization occurs in the predicted } \\
\text { contact alteration mineralized zone of intermediate } \\
\text { acid rocks, and the highest content of } \mathrm{W} \text { is } 613 \times 10^{-6} \text {. }\end{array}$ & $\begin{array}{l}\text { The W-Bi-Au-Mo-Co-Sn combination } \\
\text { anomaly that presents } \mathrm{W} \text { is the main factor. }\end{array}$ \\
\hline Sedimentary type & $\begin{array}{l}\text { No. } 30 \text {, No. } 32 \text { gypsum mine and } \\
\text { No. } 29 \text { placer gold mineralization } \\
\text { point }\end{array}$ & $\begin{array}{l}\text { The gypsum deposits occur in Xiali Formation }\left(\mathrm{J}_{2 \mathrm{x}}\right) \\
\text { and Qiaomoco Formation }\left(\mathrm{J}_{2 \mathrm{q}}\right) \text {, which are lagoon } \\
\text { chemical deposits. The placer gold mineralization is }\end{array}$ & $\begin{array}{l}\mathrm{Sn}, \mathrm{W}, \mathrm{Bi} \text { and } \mathrm{Au} \text { anomalies are found in the } \\
\text { gold mineralization area. }\end{array}$ \\
\hline
\end{tabular}




\begin{tabular}{|c|c|c|c|}
\hline Metallogenic type & Related ore spots and minerals & Metallogenic characteristics & Element combination characteristics \\
\hline & & $\begin{array}{l}\text { related to the mineralized rocks in the } \\
\text { intermediate-acid contact alteration zone. }\end{array}$ & \\
\hline $\begin{array}{l}\text { Sedimentary } \\
\text { hydrothermal } \\
\text { modification }\end{array}$ & $\begin{array}{l}\text { No. } 27 \text { and No. } 28 \text { zinc } \\
\text { mineralization sites }\end{array}$ & $\begin{array}{l}\text { Zinc polymetallic mineralization was developed in } \\
\text { ninety groups } P_{2 j} \text { and Bagong group } T_{3 b g} \text {. }\end{array}$ & $\begin{array}{l}\mathrm{Zn} \text { and } \mathrm{Cd} \text { are the main combination of } \\
\mathrm{Zn}-\mathrm{Cd}-\mathrm{Pb}-\mathrm{Ag} \text {. }\end{array}$ \\
\hline Volcanic type & $\begin{array}{l}\text { No. } 8 \text { medium iron lead deposit } \\
\text { and No. } 22 \text { iron ore point }\end{array}$ & $\begin{array}{l}\text { The iron mineralization occurs in the Quemoco } \\
\text { Formation }\left(\mathrm{J}_{2 q}\right) \text { in a stratiform and lenticular form, } \\
\text { which is closely related to the intermediate-basic } \\
\text { volcanic rocks and is characterized by sedimentary or } \\
\text { sedimentary hydrothermal reformation. }\end{array}$ & $\begin{array}{l}\mathrm{Fe} \text { and } \mathrm{Mn} \text { are the main combination of } \\
\text { Fe-Mn-Ti-Cr-Ni-Co-V. }\end{array}$ \\
\hline
\end{tabular}

Note: the ore and mineralization points are shown in Figure 2.

Among the six metallogenic types in this area, the moderate and low temperature hydrothermal polymetallic mineralization and volcanic iron polymetallic mineralization are dominant. Medium and low temperature hydrothermal polymetallic mineralization is closely related to intermediate-basic volcanic rocks, and its metallogenic characteristics are similar to those of ordinary volcanic hydrothermal mineralization. Therefore, it can also be considered as a volcanic type mineralization in general.

\section{Conclusion}

According to the above analysis, the appearance of W-Bi-Au-Mo-Co-Sn high temperature hydrothermal element assemblage indicates that there may be intermediate-acid intrusive rocks in the area, especially the contact alteration zone in Chuduo area. Yanshiping fault is a deep rock-conducting and rock-controlling fault, along which large-scale intermediate-basic volcanic rocks are distributed. The NW-trending fault zone represented by F4 and F5 is the fault zone of ore-conducting and ore-controlling. The most basic and important metallogenic conditions are intermediate-basic volcanic rocks and intermediate-acid intrusive rocks. The metallogenic conditions where the Wenquanbingzhan anticline is located, are obviously superior to those of the Burong syncline and Yanshiping syncline, and a large number of polymetallic deposits and mineralization points are concentrated and distributed. These deposits and mineralization points are controlled by the Chuduo-Chaqiong NW trending fault zone, and have the potential geological and geochemical conditions for forming the $\mathrm{Fe}-\mathrm{Cu}$ polymetallic ore field, which may be formed. They are iron, copper, silver, lead, zinc and polymetallic ore gathering areas. Medium and low temperature hydrothermal polymetallic mineralization and volcanic iron polymetallic mineralization are the main metallogenic types in the area. Medium and low temperature hydrothermal polymetallic mineralization is closely related to intermediate-basic volcanic rocks, and its metallogenic characteristics are similar to those of ordinary volcanic hydrothermal mineralization. Therefore, it is generally considered as a kind of volcanic type mineralization. There are copper mineralization in sandstone and zinc (lead) mineralization in limestone in this area, which are reformed by later hydrothermal process and may form sedimentary-reformed mineral resources. There may be strong crust-mantle mixed magmatism in the area of Hot Spring Ordnance Station. The $\mathrm{Cu}-\mathrm{Ag}$ polymetallic mineralization is related to deep fault activity, littoral-shallow sea sedimentary background of continental margin, volcanic rocks and subvolcanic rocks. The Qiaomoco Formation is composed of volcanic clastic rocks and terrigenous clastic materials. The $\mathrm{Fe}$ group elements in the ore-hosting clastic limestone are significantly higher than those in sandstone and tuff, indicating that the volcanic clastic rocks in this lithologic section are mainly composed of intermediate-basic rocks, and the volcanic rocks and subvolcanic rocks are important metallogenic bodies for copper-silver polymetallic deposits.

\section{References}

[1] Han Shengfu, Yang Shengde, Pan Tong, et al. Qinghai Provincial Department of land and resources, the third round metallogenic prospective zoning and prospecting target prediction in Qinghai Province [R]. 2005: 303-307.

[2] Song Yucai, Hou Zengqian, Yang Tiannan, and other "Sanjiang" sedimentary rock hosting base metal deposits: development characteristics and metallogenic model [D]. Beijing: Chinese Academy of Geological Sciences. 2012.

[3] Song Yucai, Hou Zengqian, Li Zheng, et al. Tuotuohe Chaqu Pacha $\mathrm{Pb}(-\mathrm{Zn})$ deposit: product of basin fluid activity in the context of continental collision [J]. Journal of Minerals, 2009, 29 (s1): 186-87.

[4] Song Yucai, Hou Zengqian, Yang Tiannan, et al. Basic characteristics and genetic types of the base metal deposits in the Himalaya period of Sanjiang [J]. Journal of Petrology and Mineralogy. 2011, 30 (3): 355-380.

[5] Sun Chongren, editor in chief, Qinghai geology and Mineral Resources Bureau. Qinghai lithostratigraphic [M]. 1997.

[6] Li Yong, Li Yalin, Duan Zhiming, et al. [R] Report on Regional Geological Survey of 1: 250000 Wenquanbingzhan [R]. Institute of Geological Survey, Chengdu University of Technology, 2005.

[7] Xu Guang, Liu Yujun, Chen Fawei, et al. 1: 200000 Mzhangcuoqin, Wenquanbingzhan map of geochemical instructions map [R]. Qinghai geological survey, 2004.

[8] Zheng Xiangguang, Lei Qunying, Mao Yifeng, et al. 1: 200000 Mzhangcuoqin, Wenquanbingzhan map of geochemical instructions map [R]. No. 2 Comprehensive geophysical survey team, Shaanxi Bureau of Geology and Mineral Resources. 
[9] Xiang Yunchuan, Rentianxiang, Mu Xuzan, et al. Technical requirements for the application of geochemical data [M]. Beijing: Geological Publishing House, 2010: 41-42.

[10] Yang Xiaofeng, Liu Changyuan, Zhang Tairan, et al. Geochemical prospecting methods [M]. Beijing: Geological Publishing House, 2007: 129-135.

[11] Ruan Tianjian, Zhu Youguang. Geochemical prospecting [M]. Beijing: Geological Publishing House, 1985: 127-130.

[12] Zhao Lunshan, Zhang Benren. Geochemistry [M]. Beijing: Geological Publishing House, 1988: 229-242.

[13] Ye Qingtong, Hu Yunzhong, Yang Yueqing, et al. [M] Regional geochemical background and gold-silver-lead-zinc mineralization in the "Three Rivers" region. Beijing: Geological Publishing House, 1992.

[14] Ye Tianzhu, Lu Zhicheng, Pang Zhenshan, et al. Theory and method of prospecting and prediction in exploration area [M]. Beijing: Geological Publishing House, 2014: 358-376.

[15] Pan Tong, Luo Cairang, Yi Youchang, et al. Metallogenic regularity and metallogenic prognosis of metal minerals in Qinghai Province [M]. Beijing: Geological Publishing House, 2006: 176-203.
[16] Hou Zengqian, Wang Erqi, Mo Yixue, et al. Collision orogenesis and mineralization of the Qinghai-Tibet Plateau [M]. Beijing: Geological Publishing House, 2008.

[17] Mo Yixue, Lu Fengxiang, Shen Shangyue, et al. [M] Volcanism and Metallogenesis of the "Three Rivers" Tethys. Beijing: Geological Publishing House, 1993.

[18] Deng Jun, Hou Zengqian, Mo Yixue, et al. "Sanjiang" Tethys complex orogeny and mineralization $[\mathrm{J}]$. deposit geology $[\mathrm{J}]$. Deposit Geology, 2010, 29 (1): 37-42.

[19] Hou Zengqian, Song Yucai, Li Zheng, et al. New types of $\mathrm{Pb}-\mathrm{Zn}-\mathrm{Ag}$ deposits in the collision orogenic belt of the Qinghai-Tibet Plateau: basic metallogenic characteristics and structural ore-controlling model [J]. Deposit geology, 2008, 27 (2): $123-144$.

[20] Zhang Hongrui, Yang Tiannan, Hou Zengqian, et al. Structural deformation and lead-zinc mineralization in the cha tepacha mining area, northern Sanjiang [J]. 2011, 30 (3): 467-474.

[21] Zheng Xiangguang, Lei Qunying, Li Jing, et al. Geochemical conditions of Yanshiping area in northern Sanjiang [J]. Geophysical and geochemical prospecting, 2016, 40 (5): 861-868. 